\title{
A COMPARATIVE STUDY ON NOISE POLLUTION LEVELS IN DHANMONDI AREA, DHAKA: A GEOSPATIAL ANALYSIS
}

\author{
MAHMUDA PARVIN* \\ Department of Environmental Science, Stamford University Bangladesh, \\ Dhanmondi, Dhaka 1209, Bangladesh
}

\begin{abstract}
Noise pollution has been recognized as one of the most vital environmental pollutions that affecting urban area's quality of life. Sound levels at different points of the study area have been recorded and presented spatially by geostatistical analysis. A comparison has been made between the study area data in 2019 and that of 2021. In 2021 the noise level was significantly higher despite the Covid 19 pandemic. The comparative study showed that the noise level of the study area in 2021increased significantly. Noise level data in the sample points of the study area on Friday (holiday) were also collected and found that it was higher than that of even working days, especially in the evening.
\end{abstract}

Keywords: Noise pollution, Urban area, Environment, Interpolation method, Spatial distribution

\section{Introduction}

Nowadays, noise pollution has become a significant problem in Bangladesh. In most of the divisional headquarters, the sound levels are far above the acceptable level for human hearing. Industrialization and urbanization are increasing at rapid rates. Consequently, noise pollution in urban areas is increasing day by day. Noise created by different sources like an airplane flying over, the train passing through the densely populated areas , honking cars, loud music, construction, a barking dog, etc., are considered noise pollution. According to the World Health Organization (WHO), the levels of noise pollution in some cities are critical and are seriously harming human health and activity. Noise pollution and its effect on human health has been of great concern, especially in modern cities, and is recently considered a vital issue to be solved (Amurtha et al. 2016, Mahmud and Alsubaie 2016, Pirerra et al. 2010). Day and night noise polluters in large and developed cities are insidious. In 2010, Hong Kong Environmental Protection Department received 23,678 environmental complaints most of which were due to noise pollution (Jaecker-Cueppers, 2011).

*Corresponding author: E-mail: <mahmudaalam@yahoo.com>. 
It is well established now that noise is a potential hazard to health, communication, workplaces, and enjoyable social life. Noise is becoming an indefensible interference imposed upon students' education, comfort, health, and the general human's quality of life.

Environmental noise pollution is increasing rapidly over the years due to the rapid increase in human activities such as transportation, industrialization, and urbanization (Hunashal and Patil 2012, Pathak et al. 2008). Some research groups have researched several cities of the world to study the harmful effects of environmental noise pollution on human health, comfort, and welfare (Alberola et al. 2005, Bhosale et al. 2010, Vidya et al. 2006).

Amin et al. (2014) studied the noise levels of some CNG stations at Sylhet at different times, and they found that noise levels were higher than the permissible noise levels. The temporal and spatial dynamics of urban traffic-induced noise pollution at various locations of Pabna at different times of the day were studied by Arifuzzaman and Razu (2015). They also found that noise levels of the study areas were also higher compared to the standard noise levels. The status of noise pollution at the major intersections in the Khulna metropolitan city was assessed by Sultana et al. (2020). It was reported that noise levels in diverse areas were higher than in commercial areas. Earlier noise levels at different locations of Dhaka city were studied by some research groups (Chowdhury et al. 2010, Riyad et al. 2020). But the noise level of Dhanmondi was not studied recently. This study attempts to assess the noise pollution of Dhanmondi, an important area of Dhaka city, established as residential area but over period turned to a mixed area of residential, commercial and others.

Objectives of the study: The objectives of the study comprise the following: (i) To assess the noise levels at different locations of the Dhanmondi area, (ii) To compare the noise levels of the study area based on time, locations, working hours, etc. (iii) To show the spatial distribution of noise levels of the study area.

Study area: Dhanmondi (ward DSCC 15), situated in Dhaka South City Corporation, was selected (Fig. 1). It is situated between $23^{\circ} 44^{\prime} 12^{\prime \prime}$ and $23^{\circ} 45^{\prime} 22^{\prime \prime}$ north latitudes and between $90^{\circ} 22^{\prime}$ and $90^{\circ} 23^{\prime}$ east longitudes. Noise levels at 40 sample points of the study area have been collected. These points were not selected at a specific distance from each other, instead it was measured around places like shopping mall, schools, hospitals, roadsides, commercial places, etc. The surrounding neighborhood is characterized by residential houses generally comprised of 4-5 floors. From Fig. 2, it was found that 8 sample points belonged to the residential zone, 7 sample points belonged to the mixed 
zone, 7 sample points were in commercial area (Shopping mall, bank, other offices) and 3 sample points were in silent zone (Primary school, hospital) and 4 in recreational place (Abahoni playground, lake side park, etc.) and rest of the sample points belonged to roadside and road intersections. Many important organizations, offices, hospitals, educational institutions, residences, lakes etc. are situated in the study area. The major roads are important for urban and national connectivity and have all modern facilities. Fig. 2 showed the land use pattern of the study area with sample locations.

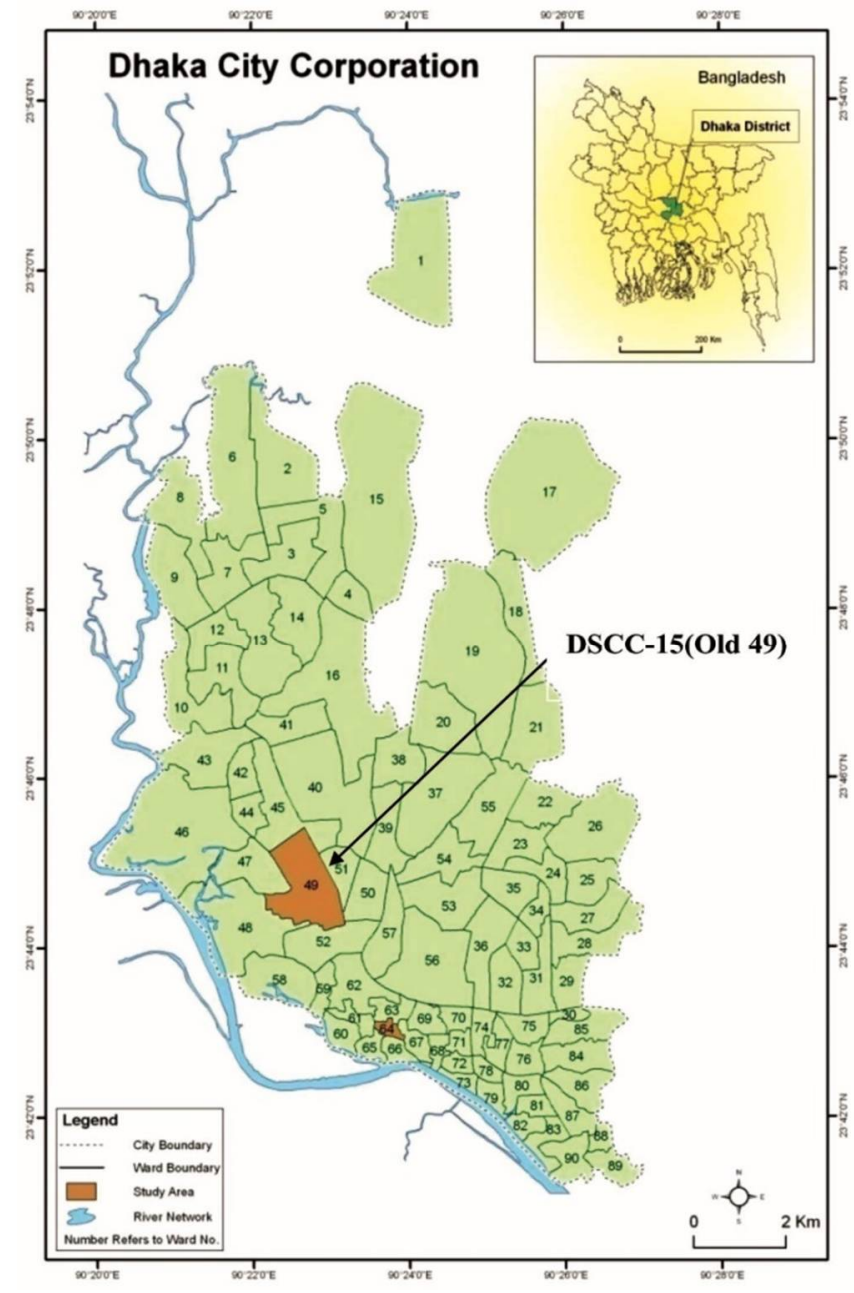

Fig. 1. Map of the study area, Dhanmondi, DSCC-15 (Old-49). 


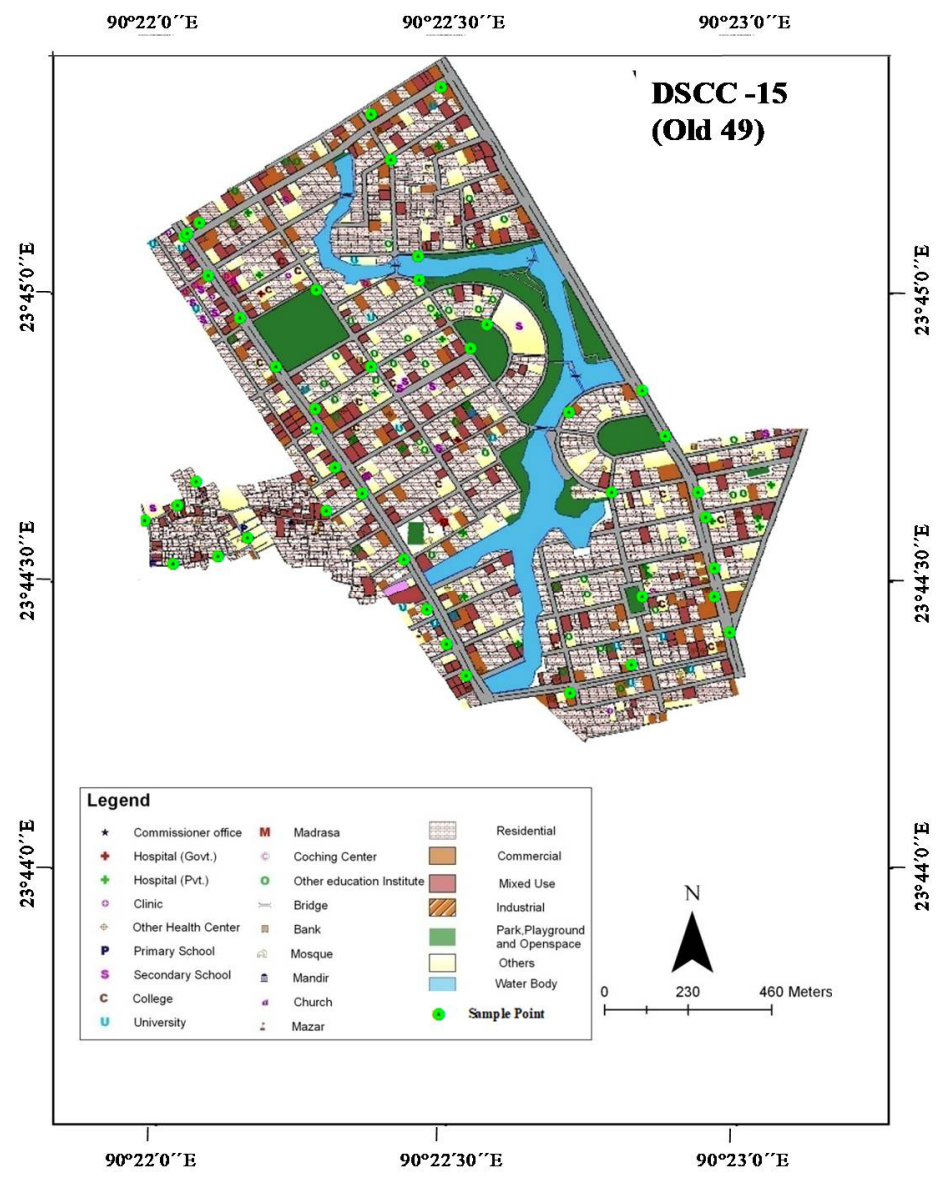

Fig. 2. Land use map of Ward DSCC-15 with sample locations.

In this densely populated city, certain important areas are being used for multidimensional purposes increasing noise pollution potentiality. Environmental Conservation Act-1995 (ECA'95) and Environmental Conservation Rules 1997 (ECR'97), (Rule 12, Schedule-4) categorize areas to point out standards of sound.

\section{Methodology}

In this study, the interpolation method was used for the study area's spatial distribution of noise levels. Several interpolation methods include linear interpolation, Inverse Distance Weighting (IDW), Natural Neighbor Inverse Distance Weighted (NNIDW), Spline and Kriging, etc. The spatial distribution of noise levels in Dhanmondi in the years 2019 and 
2021 was done with the IDW method. Based on the noise levels behavior of the locations in the study area IDW method was selected for generating noise color contour. It is one of the most commonly used techniques with higher accuracy than other interpolation methods (Moteallemi et al. 2017). It weighs each point by the inverse of the distance after the reference point assigned for each measurement. It provides an exact weighted interpolated surface grid. Furthermore, IDW offers satisfactory results for predicting noise level maps.

The following equation can express the IDW interpolation formula:

$$
x^{*}=\frac{w_{1} x_{1}+w_{2} x_{2}+w_{3} x_{3}+\ldots . .+w_{n} x_{n}}{w_{1}+w_{2}+w_{3}+\ldots .+w_{n}}
$$

where, $\mathrm{x}^{*}$ is the unknown value at a location to be determined, $\mathrm{w}$ is the weight, and $\mathrm{x}$ is the known point value. The weight is an inverse distance of a point to each known point value used in the calculation. Simply the weight can be calculated using the following equation.

$$
w_{1}=\frac{1}{d_{i x^{*}}^{p}}
$$

Data standardization: Several sound level data were taken at each location point with a VOLTCRAFT digital noise level meter SL-50. Then, they were averaged to get the final sound level value. The data were collected above 1.5 meters above the ground surface to avoid the noise generated by the wind condition. The data were averaged because a place's sound level varies due to different types of sources common in the study area, such as traffic signals, honking, crowd, etc.

Data analysis and interpretation: Arc GIS 10.4.1 software was used in data analysis and interpretation. Noise level contour map and surface were generated based on noise level data collected from the different points of the study area. Noise level color contours were produced using different intervals, which depict the spatial variation of noise. Bangladesh transverse mercator (BTM) projection system was used in this study.

\section{Results and Discussion}

Dhaka city is one of the most densely populated cities in the world. Dhanmondi which belongs to Dhaka South City Corporation, is a significant residential and commercial place. Many academic institutions, hospitals, clinics, and offices are situated in that area. 
So, maintaining noise pollution to a certain limit is very important for the policy makers. Maximum acceptable noise level varies from place to place. Namely, noise levels at silent zone, residential and commercial areas are different. The standard values of noise level at different areas are presented in Table 1.

Table 1. Noise quality standards, by zone and time of day.

\begin{tabular}{lcc}
\hline \multirow{2}{*}{ Zone Class } & \multicolumn{2}{c}{ Limits in dB (decibel) } \\
\cline { 2 - 3 } & $\begin{array}{c}\text { Daytime } \\
(\mathbf{6} \mathbf{~ a m - 9 ~} \mathbf{~ m})\end{array}$ & $\begin{array}{c}\text { Nighttime } \\
\mathbf{( 9} \mathbf{~ p m - 6 ~} \mathbf{~ a m})\end{array}$ \\
\hline Silent zone & 45 & 35 \\
Residential zone & 50 & 40 \\
Mixed(residential/commercial/industrial)zone & 60 & 50 \\
Commercial zone & 70 & 60 \\
Industrial zone & 75 & 70 \\
\hline
\end{tabular}

Source: Unnayan Shamannay, People's Report on Bangladesh Environment 2001.

Recently, the spatial distribution of noise levels in Ward DSCC 15 in the year 2007 was demonstrated by Parvin et al. (2016). It was found that noise levels of most of the points of the study area were found to be higher than the permissible limit. These data were used to compare the present research outcomes.

In November 2019 and in March 2021, the noise levels of the Ward DSCC 15 were measured during the periods of $8 \mathrm{am}-10 \mathrm{am}, 12 \mathrm{pm}-2 \mathrm{pm}$ and $5 \mathrm{pm}-7 \mathrm{pm}$ of the working day. Despite having modern facilities and well-planned constructions, a similar type of distribution as of 2007 reported by Parvin et al. (2016) was observed. But the range of noise levels in 2019 and 2021 werecomparatively higher.

On the working day of the year 2019, the noise level of the study area ranged from 69-85 $\mathrm{dB}$ in the morning, that of 2021 was 63 to $84 \mathrm{~dB}$ (decibel) and the noise level ranged from 71 to $89 \mathrm{~dB}$ during the holiday (Fig. 3). All the noise level values were higher than the acceptable limits for roadside, residential area, near the hospital and in the commercial area. The high noise level occurs during the daytime as people travel to and from schools, markets, and workplaces (Ahmad and Khan 2003). The severities of noise pollutions were higher in the morning on Friday. The range is lower in 2021 compared to 2019 because of Covid 19. All educational institutes were closed. So, students' movements were not found. 


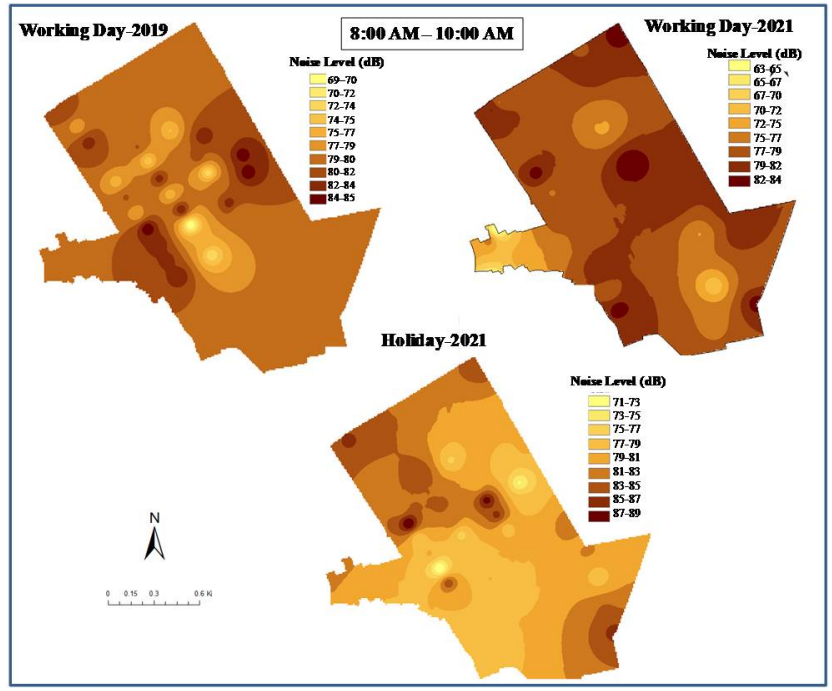

Fig. 3. Spatial distribution of noise levels in Ward DSCC 15 from 8:00 to 10:00am in 2019 and 2021.

The spatial distribution of noise levels of the study area from $12.00 \mathrm{pm}-2.00 \mathrm{pm}$ in the years 2019 and 2021 is shown in Fig. 4.

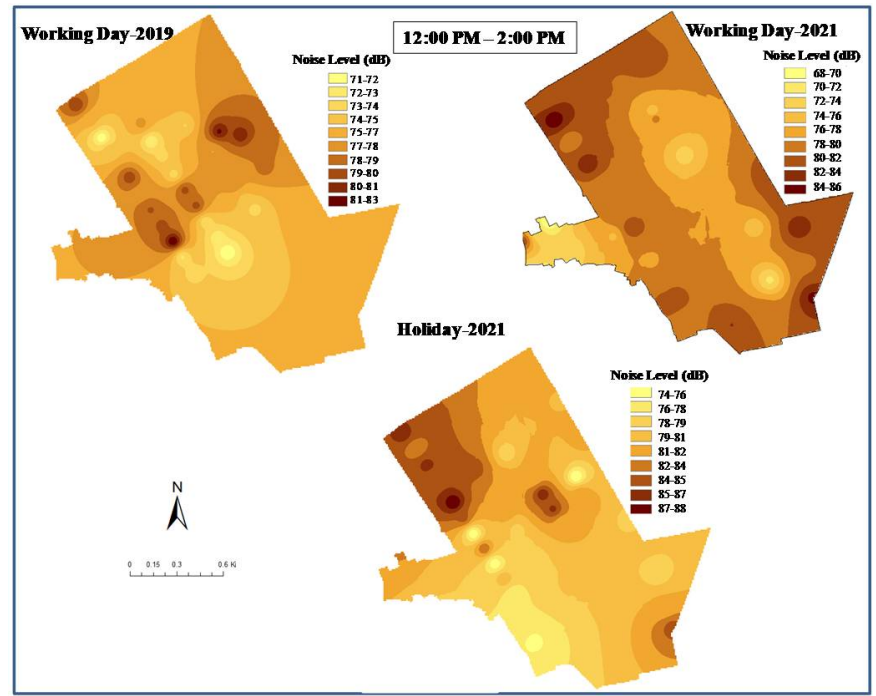

Fig. 4. Spatial distribution of noise levels in Ward DSCC 15 from 12:00 to 2:00pm in 2019 and 2021. 
Fig. 4 revealed that the noise levels in the study area were also higher than the acceptable limit during the working day in 2019 and 2021. In the noon, the noise level was slightly higher than that of 2019 though all the educational institutes were closed due to Covid 19 pandemic. The tendency was increasing in the study area day by day. In the noon (12 pm$2 \mathrm{pm}$ ), the noise level ranges in 2019 were $71-83 \mathrm{~dB}$, and in 2021 were $68-86 \mathrm{~dB}$ and $74-$ $88 \mathrm{~dB}$ on Friday, 2021. The lake area and adjacent residential area showed comparatively lower noise pollution. Landuse pattern map of the study area (Fig. 2) exhibits that the left side of the Satmosjid road (near Jigatola and Mitali road) are mostly covered by residential area. This area showed a relatively lower level of noise (77-79 dB) in 2019 (70-76 dB) in 2021 at noon, but that is also higher than the standard level for the residential area.

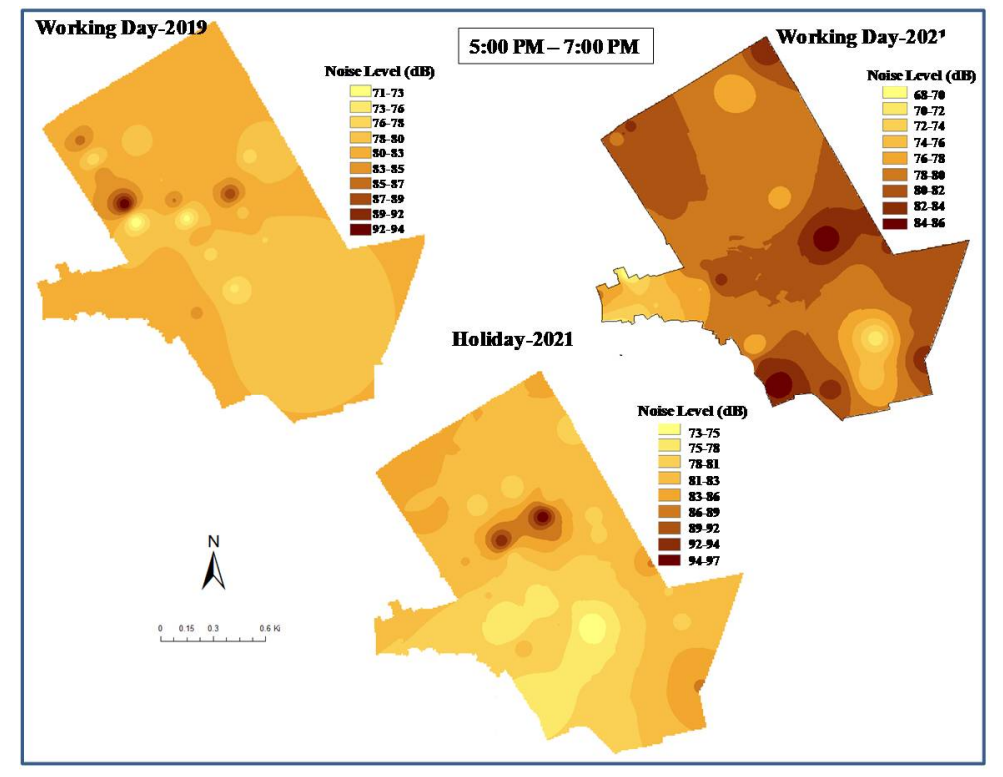

Fig. 5. Spatial distribution of noise levels in Ward DSCC 15 from 5:00 to 7:00 pm in 2019 and 2021.

An attempt was made to explore the noise level situation in the evening. From Fig. 5, it was found that the ranges of noise levels varied from 71-94 dB, 68-86dB, and 73-97 dB in the evening during the working day in 2019,2021 , and in holiday 2021, respectively. The severity was lower in 2021 than that of 2019 because of the closure of educational institutes due to the Covid 19 Pandemic. In the evening, the severity was higher on 
holiday than a working day in 2021 in recreational places near Dhanmondi bridge, Rabindra Sorobar, Dhanmondi Women's complex etc. In the Ward DSCC 15, the noise level value is too high on Friday in the cross-section of road 16 and Satmosjid road (Commercial pace and diverse area). Most of the time, the value was higher than $80 \mathrm{~dB}$. The north-western part of the study area always showed a noise level of higher than 80 $\mathrm{dB}$ because of increased recreational movements.

\section{Conclusion}

Noise levels of the Dhanmondi area in 2019 and 2021 at different periods have been measured and shown spatially by IDW interpolation methods. Noise levels of the study area in 2007 were collected from the literature. A comparative study has been carried out to explore the trend of increasing noise pollution. In 2007, the maximum noise level was $72 \mathrm{~dB}$, whereas, in 2019 and 2021 the maximum noise level in the morning was $94 \mathrm{~dB}$ and $86 \mathrm{~dB}$, respectively. Thus, noise pollution in the study area is increasing day by day. Sensitive institutions, e.g., schools and hospitals, should be located about $60 \mathrm{~m}$ away from the roadside. The Government of our country is concerned about this issue. Recently, some selected areas of Dhaka City have been declared as Silent Zone, and law enforcement agencies are working on it. Some motivational works and advertisements could be done to develop awareness among the mass.

\section{References}

Ahmad, A.J and J.A. Khan. 2003. Traffic noise control in the city. NED Engineering Horizons. XVI. 174.

Alberola, J., H. Flindell, and J. Bullmore. 2005. Variability in road traffic noise levels, European Commission environmental noise directive 2002/49/EC; Off. J. Eur. Communities. 189: 12-25.

Amin, N., I. Sikhder., M.A. Zafor and M.A.I. Chowdhury. 2014. Assessments of noise pollution of two vulnerable sites of Sylhet city, Bangladesh. Int. J. Water Res. Environ. Eng. 6(1): 112120.

Amurtha, P.P., M. Sravani, K. M. Ashok, P. Sowmya, and S.P. Naga. 2016. Noise pollution and its impact on human health and social behavior using system approach-A case study in Kurnool city, India. Civil Environ. Res. 8(7): 70-80.

Arifuzzaman, K. and S.M.H. Razu. 2015. Road traffic noise pollution: present scenario and potential noise attenuation strategy for Pabna Municipality, Bangladesh. Int. J. Adv. Res.3(4): 782-789.

Bhosale, B.J., P.M. Nalawade, S.P. Chavan and M.B. Mule. 2010. Studies on assessment of traffic noise level in Aurangabad city, India. Noise Health. 12(48): 195-196.

Chowdhury. S.C, M.M. Razzaque and M.M. Helali. 2010. Assessment of noise pollution in Dhaka city. The $17^{\text {th }}$ International conference on sound and vibration. Cairo, 18-22 July. 
The Bangladesh Environment Conservation Act, 1995.

ECR. 1997. The Environment Conservation Rules, Government of the People's Republic of Bangladesh, Ministry of Environment and Forest. 205-207.

Jaecker-Cueppers, M. 2011. Urban Transport and Health, Module 5c, Division 44, Noise and its Abatement, a source book for policy maker, GIZ publication.

Hunashal, R.B. and Y.B. Patil. 2012. Assessment of noise pollution indices in the city of Kolhapur, India. Procedia Soc.Behav. Sci. 37:448-457.

Mahmud, F.E-S. and A. Alsubaie. 2016. Study of Environmental noise pollution in the University of Dammam Campus. Saudi. J. Med. Med. Sci. 2(3):178-184.

Moteallemi, A., B. Bina., M. Minaei. and S. Mortezaie. 2017. The evaluation of noise pollution at Samen district in Mshhad, Khorasan Razavi Province, Iran using geographic information system. Int. J. Occup. Hyg. 9(4):179-185.

Pathak,V., B.D. Tripathi and V.K. Mishra. 2008. Evaluation of traffic noise pollution and attitudes of exposed individuals in working places. Atmos. Environ. 42(16): 3892-3898.

Pirerra, S., E. Devalck and R. Cluydts. 2010. Nocturnal road traffic noise: A review on its assessment and consequences on sleep and health. Environ. Int. 36 (5): 492-498.

Parvin, M., M.I. Hossain. andA.U. Khan. 2016. Spatial distribution of noise pollution in Dhaka City: a geo-statistical modelling, Stamford J. Environ. Hum. Habitat. 5: 14-23.

Riyad, R.H., A. Amin. and M. Mazumder 2020. A study of noise pollution by traffic during peak and offpeak hour in Dhaka city. Journal of Innovations in Civil Engineering and Technology. 2(2): 43-53.

Sultana, A., A.K. Paul and M.U. Nessa. 2020. The status of noise pollution in the major traffic intersection in Khulna metropolitan city in Bangladesh its possible effects on noise-exposed people.Eur. J. Environ. Sci. 1(5): 1-8.

UnnayanShamannay, People's Report on Bangladesh Environment. 2001. The University Press Limited (UPL).

Vidya, S.B., T. Nageswara and G. Rao. 2006. Noise pollution levels in Visakhapatnam city (India). Environ. Sci. Eng. 48(2): 139-134.

(Revised copy received on 01.09.2021) 